\title{
Hemodynamic Findings in Normal Children
}

\author{
L.J. Krovetz, T.G. McLoughlin, M.B. Mitahell and G.L. Schiebler \\ Department of Pediatrics, J. Hillis Miller Health Center, University of Florida, \\ Gainesville, Florida, USA
}

\begin{abstract}
Extract
We have studied cardiac function and dynamics in 29 apparently normal children under 20 years of age.

Table I lists the values obtained for intracardiac and great vessel pressures. There was no correlation of these pressures with either age or increasing body size. Except for the possibility that our data is inadequate for patients under one week of age, these pressures as well as the ratio between pulmonary artery mean to systemic artery mean (fig. 1), appear to be constant throughout the pediatric age range. Arterio-venous differences ranged from 28 to $78 \mathrm{ml}$ of $\mathrm{O}_{2} / 1$ of blood. The mean was $44.3 \mathrm{ml} / 1$ with a S.D. of 15.0 .

Left ventricular cavity diameters are shown for 11 normal children from our series and 9 patients from the literature (fig. 4). The two measurements recorded in the youngest subjects are elevated, probably as a result of our inability to distinguish that area of left ventricular 'wall' occupied by the thymus. The ratio of the left ventricular cavity diameter to wall thickness was 7.0 (fig. 5).

Calculated systemic, total pulmonary and pulmonary arteriolar resistances appeared to be inversely related to age, height, and weight. Therefore, it seemed that non-linear regression formulae employing the inverse of age, height and weight would be more suitable (table III). Height alone gave the best correlation with all cardiac functions except output.

Calculated resistances for both systemic and pulmonary circulations fall with increasing age at approximately the same rate (figs. 6-8). As systemic blood flow increases to accommodate the needs of increasing body size, the denominator of the DC resistance term increases and 'resistance' decreases. Since in the absence of shunts, pulmonary blood flow must parallel the increase in systemic blood flow, pulmonary 'resistance' decreases pari passu.
\end{abstract}

\section{Speculation}

High speed digital computers now make the development of regression equations increasingly simple. These equations will be increasingly employed by clinical investigators in place of 'surface area'.

It is also obvious that calculated 'resistances' tell us far less about the vascular bed than was formerly believed. Input impedance calculation will be employed in the future, particularly as better methods for measuring instantaneous flow become available. 


\section{Introduction}

Since the introduction of cardiac catheterization in man $[6,10]$, numerous reports have appeared in the literature which define the normal range of pressures and flows. Most of these data have been obtained from normal adult volunteers. A more limited amount of information is available concerning normal children $[1,4,5,16,18,19,22-24,26]$. Furthermore, the data presented rarcly offers all or even most of the parameters of interest. For example, we have been unable to find any measurements of left ventricular enddiastolic pressures in this age group. It is the purpose of the present communication to present a detailed analysis of normal cardiovascular findings in a group of apparently normal children.

Altnough surface area is commonly used to compare individuals of varying body size [14], the data presented in this report fail to support the validity of this usage. The authors advocate the use of regression equations, which involve only easily measured facts regarding the patient.

\section{Materials and Methods}

During the past 4 years, we have studied 25 children under 20 years of age who met the following criteria of normality: 1. absence oî cardiovascular symptoms, 2. normal electrocardiogram and thoracic roentgenograms, and 3. right ventricular-pulmonary artery systolic pressure difference of less than $15 \mathrm{~mm} \mathrm{Hg}$ [4]. In all cases where the pre-catheterization diagnosis included a left-to-right shunt, these were excluded by a sensitive technique, including 10 double catheter sampling techniques and 8 selective angiocardiograms.

The choice of $15 \mathrm{~mm} \mathrm{Hg}$ in criterion 3 is arbitrary as it is difficult to define a RV-PA systolic pressure difference that will exclude all cases of mild pulmonic stenosis. Above this level, however, we have generally found electrocardiographic evidence of right ventricular hypertrophy.

These children were catheterized for a variety of reasons, including unusual innocent murmurs [13], idiopathic dilatation of the pulmonary artery [4], apparent cardiomegaly [5], pectus excavatum [2], localized pulmonary sequestration [1], and mild pulmonic insufficiency without electrocardiographic evidence of right ventricular hypertrophy [1].

In addition, three infants who failed to meet criterion 1 or 2 were included since adequate catheterization data is rare in this age group. These included two infants with unilateral pulmonary hypoplasia and one infant who was catheterized following spontaneous closure of both a ventricular septal defect and a patent ductus arteriosus.
Seventeen older children who failed to meet one or more of these criteria were excluded even though they were considered to have innocent murmurs or idiopathic dilatation of the pulmonary artery.

All patients werc catheterized in a supine position. No premedication was given to infants under one year of age. Children over this age were given a single intramuscular dose of demerol $(1 \mathrm{mg} / \mathrm{kg})$, Phenergan $(0.25$ $\mathrm{mg} / \mathrm{kg})$ and thorazine $(0.25 \mathrm{mg} / \mathrm{kg})$.

The mid-chest level was selected for the zero pressure level. Statham P23 Dd and P23 Gb transducers were used and tracings recorded on a Honeywell ultraviolet oscillograph (Model 1108). All pressure recording systems were calibrated against a mercury manometer at least once during each cardiac catheterization. A square-wave step of pressure to $300 \mathrm{~mm} \mathrm{Hg}$ was used to test the system for optimal damping. Pressure tracings that were obviously overdamped or underdamped were discarded. First derivatives of right and left ventricular pressure $(\mathrm{dp} / \mathrm{dt})$ were obtained by averaging maximum positive slopes of at least 5 pressure cycles.

Arterio-venous differences were measured in blood samples withdrawn simultaneously from the main pulmonary artery and a systemic arterial sampling site over a period of approximately 1 minute. Oxygen saturations and arterial blood oxygen-binding capacitics were determined by the Van Slyke-Neill method.

Cardiac outputs were calculated from indicator dilution curves employing single, rapid right heart injections of indocyanine grcen with systemic arterial sampling. The Waters XC-250 densitometer ${ }^{1}$ was calibrated by adding known amounts of dye to the subject's arterial blood. Dye concentrations were measured at 0.5 or 0.1 second intervals using a semi-automatic analog-to-digital converter (Gerber Oscillogram Amplitude Tabulator $\left.{ }^{2}\right)$. Cardiac outputs were calculated by the Stewart-Hamilton method using an IBM 709/ 1401 computing system. ${ }^{3}$

The numerical values obtained were entered on IBM cards. Ages were converted to decimal fractions and recorded in years to the nearest 0.001 . Means, standard deviations and standard errors were calculated by a BMD program [7]. Regression coefficients were calculated by using the BMD stepwise linear regression program.

Published data on 123 normal subjects under 20 years of age was tabulated and used for comparison purposes $[1,4,5,16,18,19,22-24,26]$. As can be seen from table I, the data were often incomplete. For example, pulmonary artery pressure was reported in 92

\footnotetext{
1 Waters Corporation, Rochester, Minn.

${ }^{2}$ Gerber Scientific Instrument Co., Hartford, Conn.

${ }^{3}$ KROVETz et al.: to be published.
} 
instances, systemic arterial pressure in 42 instances and both in only 35 .

Vascular resistances were calculated according to the following formulac:

Systemic resistance $=$

mean systemic arterial pressure-mean right atrial pressure cardiac output

Total pulmonary resistance $=$ mean pulmonary artery pressure cardiac output

Pulmonary arteriolar resistance $=$ mean pulmonary artery pressure-mean left atrial pressure

cardiac output
The results of these calculations are given in peripheral resistance units (P.R.U.), the units of which are $\mathrm{mm} \mathrm{Hg} / 1 / \mathrm{min}$.

Left ventricular stroke work was calculated as stroke volume $\mathrm{x}$ mean systemic artery pressure minus left ventricular end-diastolic pressure $\times 1334 \div 10^{7}$, the units of which are Newton-meters or joules.

Thickness of the left ventricular wall (W) and AP diameter of the left ventricular cavity $(C)$ were determined by the angiocardiographic method of LEvine, RockofF and Braunwald [17]. Cineangiocardiography was employed in 7 cases and biplane serial films in 4 cases. The projection distance for cineangiographic films was adjusted so that the thoracic cage silhouette was equal to that obtained on plain teleroentgenographic films. Since our data were limited to only 11 children, measurements reported by НАТАM, RUDHE and WALLGREN [12] on seven normal children were included for the regression equation of wall thickness. In this latter report the average of several LV

Table I. Comparison of selected hemodynamic data

\begin{tabular}{|c|c|c|c|c|c|c|c|c|c|c|c|}
\hline & & & \multicolumn{5}{|c|}{ Present report } & \multicolumn{4}{|c|}{ Literature } \\
\hline & & & Units & No. & Mean & S.D. & Range & No. & Mean & S.D. & Range \\
\hline Agc & $\cdot$ & . . & Years & 30 & 8.7 & 5.8 & $0.003-19.9$ & 123 & 9.0 & 5.8 & $0.001-19$ \\
\hline Arterio-venous differe & nce & . & $\mathrm{ml} / \mathrm{L}$ & 23 & 44.3 & 15.0 & $20-78$ & 90 & 39.1 & 8.2 & $24-66$ \\
\hline Cardiac index . . . & . & . . & $\mathrm{L} / \mathrm{min} / \mathrm{m}^{2}$ & 21 & 4.32 & 0.7 & $3.3-5.7$ & 72 & 4.5 & 1.3 & $2.5-9.2$ \\
\hline Stroke volume index & 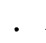 & . . & $\mathrm{ml} / \mathrm{m}^{2}$ & 21 & 44.3 & 15.0 & $22.7-82.6$ & 52 & 48.1 & 13.3 & $26.2-81.8$ \\
\hline Oxygen cons $/ \mathrm{m}^{2}$. & . & . . & $\mathrm{ml} / \mathrm{m}^{2}$ & 8 & 141.8 & 20.1 & $114.0-165.4$ & 68 & 167.7 & 32.3 & $87.1-268.2$ \\
\hline LV cavity/wall . . & - & . . & 一 & 11 & 7.0 & 1.9 & $3.8-10.5$ & None & & & \\
\hline $\mathrm{PA} / \mathrm{SA}$ mean... & . & . . & - & 28 & 0.15 & 0.03 & $0.11-0.23$ & 35 & 0.21 & 0.12 & $0.04-0.93$ \\
\hline \multicolumn{12}{|l|}{ Systemic artery } \\
\hline systolic . & . & . . & $\mathrm{mm} \mathrm{Hg}$ & 29 & 111.1 & 13.0 & $77-138$ & 36 & 110.3 & 26.2 & $48-152$ \\
\hline diastolic . . . . & . & . . & $\mathrm{mm} \mathrm{Hg}$ & 29 & 64.2 & 9.8 & $48-88$ & 36 & 63.2 & 14.2 & $28-84$ \\
\hline mean ..... & . & . . & $\mathrm{mm} \mathrm{Hg}$ & 29 & 80.5 & 11.6 & $57-109$ & 42 & 79.0 & 18.0 & $38-112$ \\
\hline \multicolumn{12}{|l|}{ Pulmonary artery } \\
\hline systolic. . . & ${ }^{\circ}$ & . . & $\mathrm{mm} \mathrm{Hg}$ & 28 & 21.8 & 6.2 & $12-42$ & 86 & 22.4 & 9.5 & $6-60$ \\
\hline diastolic . . . . & - & . . & $\mathrm{mm} \mathrm{Hg}$ & 28 & 8.7 & $2 \cdot 8$ & $4-18$ & 86 & 9.6 & 6.0 & $2-42$ \\
\hline mean . . & . & . . & $\mathrm{mm} \mathrm{Hg}$ & 28 & 12.4 & 3.1 & $6-22$ & 92 & 14.2 & 7.1 & $3-49$ \\
\hline \multicolumn{12}{|l|}{ Right ventricle } \\
\hline systolic . . . . & • & . . & $\mathrm{mm} \mathrm{Hg}$ & 27 & 28.0 & 5.9 & $9-42$ & 48 & 32.9 & 14.7 & $16-80$ \\
\hline end-diastolic . . & . & . . & $\mathrm{mm} \mathrm{Hg}$ & 26 & 5.0 & 1.9 & $1-8$ & 48 & 3.3 & 3.1 & $-1-13$ \\
\hline $\begin{array}{l}\text { left atrial mean or } \\
\text { pulmonary artery }\end{array}$ & & & & & & & & & & & \\
\hline mean .... & . & . . & $\mathrm{mm} \mathrm{Hg}$ & 18 & 7.0 & 2.3 & $3-12$ & 39 & 6.8 & 3.9 & $-2-14$ \\
\hline right atrial mean. & . & . . & $\mathrm{mm} \mathrm{Hg}$ & 8 & 3.8 & 2.0 & $1-8$ & 47 & 2.6 & 2.8 & $-3-9$ \\
\hline \multicolumn{12}{|l|}{ Left ventricle } \\
\hline end-diastolic . . & & $\cdot$ & $\mathrm{mm} \mathrm{Hg}$ & 13 & 7.5 & 2.2 & $4-11$ & \multicolumn{4}{|c|}{ No data } \\
\hline $\mathrm{RV} \mathrm{dp/dt.} \mathrm{.} \mathrm{.} \mathrm{.}$ & . & . . & $\mathrm{mm} \mathrm{Hg} / \mathrm{sec}$ & 15 & 360 & 142 & $235-840$ & \multicolumn{4}{|c|}{ No data } \\
\hline $\mathrm{LV} \mathrm{dp} / \mathrm{dt} .$. & . & . . & $\mathrm{mm} \mathrm{Hg} / \mathrm{sec}$ & 15 & 2178 & 647 & $1204-3260$ & \multicolumn{4}{|c|}{ No data } \\
\hline
\end{tabular}


wall measurements were employed, but the results were not significantly different from those obtained by the simpler method of Levine et al. [17].

\section{Results \\ Pressures}

Table I lists the values obtaincd for intracardiac and great vessel pressures, which were generally similar to those in the literature $[1,4,5,16,18,19,22-24,26]$. There was no correlation of these pressures with either age or increasing body sizc. Emmanouilides et al. [8] have shown that the elevated pulmonary artery pressures found after birth decline gradually during the first three days of life, probably reaching normal adult values by about one week of age. Our only subject under one week of age had a pulmonary artery pressure of $42 / 4 \mathrm{~mm} \mathrm{Hg}$, with a mean of $17 \mathrm{~mm} \mathrm{Hg}$.

With the proviso that our data are inadequate under one weck of age, these pressures as well as the ratio between pulmonary artery mean to systemic artery mean (fig. 1), may be considered constant throughout the pediatric age range.

Differentiation of pressure curves is dependent on the upper frequency response of both the recording and derivative circuits [9]. Since our method utilized conventional pressure recording techniques which are limited to a maximum of about $20 \mathrm{cps}$, our values differed from those obtained using a faster-responding catheter-tip micromanometer. Table II compares our results with those of GLEAson and BRAUNwald [11] who used catheter-tip transducers with a differentiating circuit and Miller, KIRKLin and SwaN [21] who used conventional manometry and an electric differentiating circuit. Because of these variations in technique the values obtained are sufficiently different that normal values are not interchangeable.

\section{Arterio-zenous Oxygen Difference}

Arterio-venous differences ranged from 28 to $78 \mathrm{ml}$ of $\mathrm{O}_{2} /$ liter of blood. Figure 2 presents our data in addition to cumulated data from the literature $[1,4,5,14$, 16-19, 22-24, 26] plotted against age. The mean was $44.3 \mathrm{ml} / 1$ with a S.D. of 15.0 . This is similar to the mean values reported by others (table I) but the $S$.D. in our series was nearly twice that of the combined reports. At least in our hands, this is only a fair indicator of normality since our range was so large.

\section{Left Ventricular Measurements}

Left ventricular cavity diameters are shown for 11 normal children in figure 3 . To supplement our 11 measurements of $L V$ wall thickness, we have included 9 measurements recorded by Hatam et al. [12] (fig. 4). Although the methods differ slightly the results appear

9 Pediat. Res., Vol. 1, No. 2 (1967)
Table II. Averagc peak first derivative of ventricular pressures pulses

\begin{tabular}{|c|c|c|}
\hline & $\begin{array}{l}\text { Right } \\
\text { ventricle }\end{array}$ & $\begin{array}{l}\text { Left } \\
\text { ventricle }\end{array}$ \\
\hline GLEason and Braunwald [11] & $\begin{array}{l}248 \mathrm{~mm} \\
\mathrm{Hg} / \mathrm{sec}\end{array}$ & $\begin{array}{l}1219 \mathrm{~mm} \\
\mathrm{Hg} / \mathrm{sec}\end{array}$ \\
\hline Miller, KiRkLin and Swan [21] & 一 & $>900$ \\
\hline Present report & 462 & 2178 \\
\hline
\end{tabular}

Pulmonary arterial mean

Systemic arterial mean

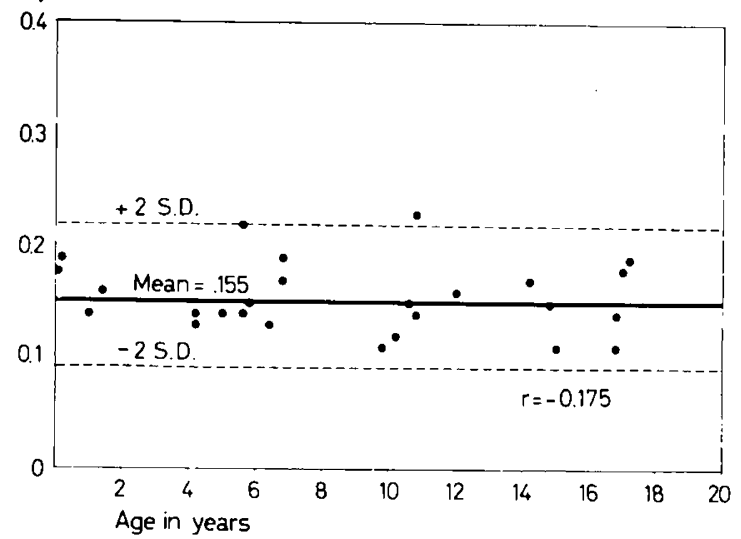

Fig. 1. Ratio of mean pulmonary artery pressure to mean systemic artery pressure at various ages. After the first week or two of life, this ratio is constant.

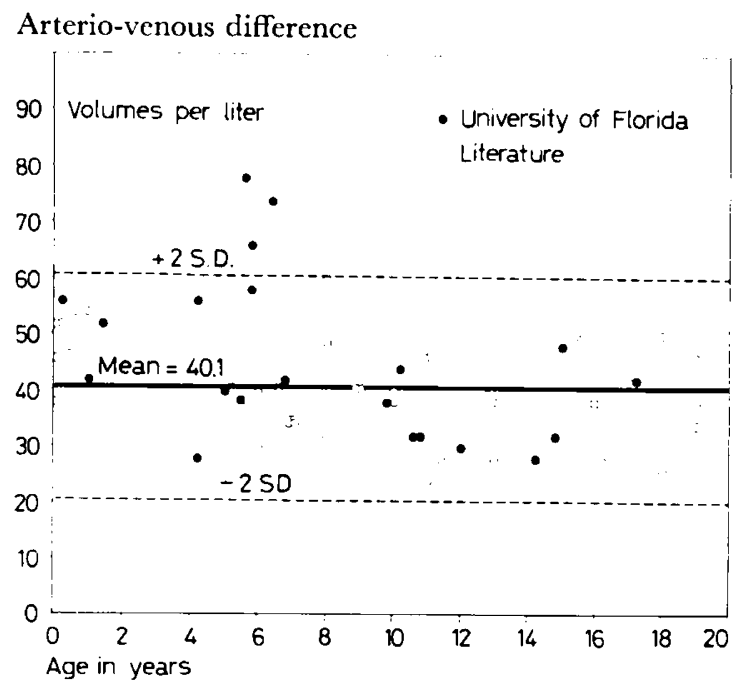

Fig.2. Arterio-venous oxygen differences plotted against age. This figure includes data from references $[1,4,5,19,23,24,26]$ as well as our own laboratory. 
Left ventricular cavity

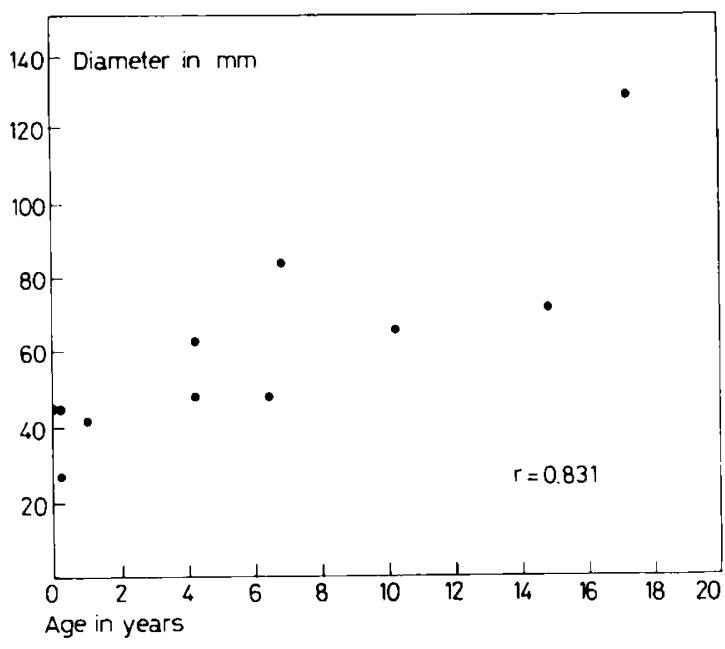

Left ventricular wall

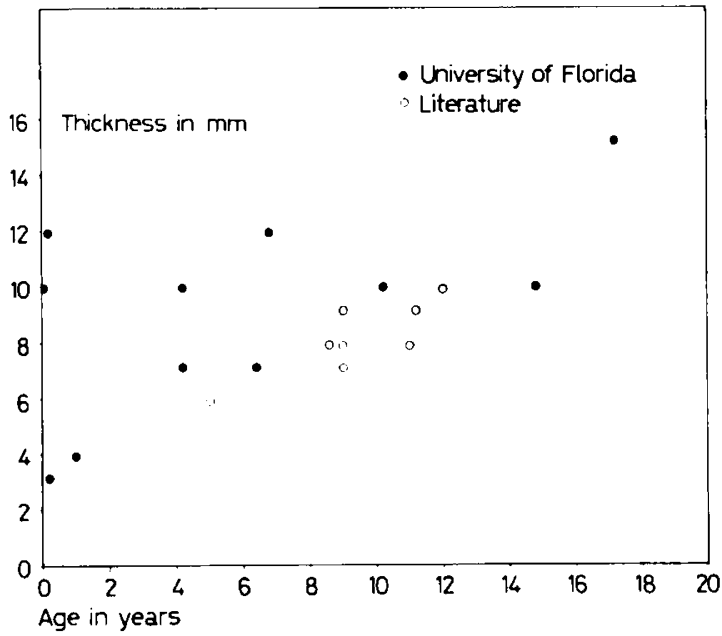

Left ventricular cavity/wall

Fig. 5

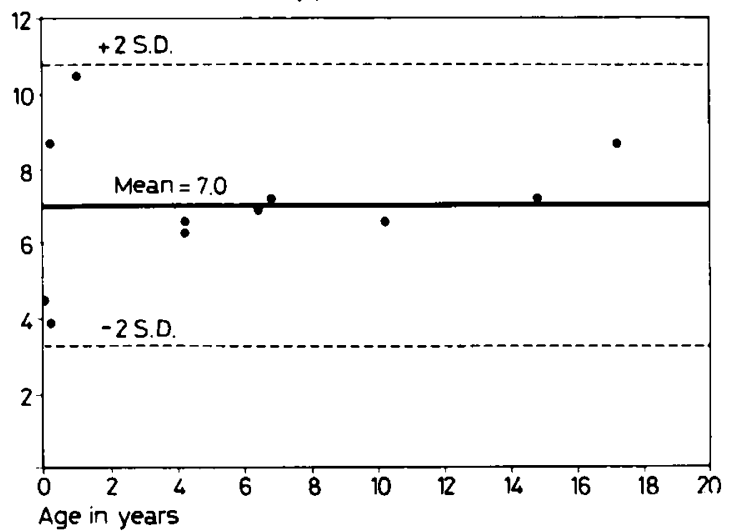

to be comparable. The two measurements recorded in our youngest subjects are elevated, probably due to the inability to distinguish that area of LV 'wall' occupied by the thymus.

The ratio of $\mathrm{LV}$ cavity diameter to wall thickness is of value in differentiating various left heart lesions [17]. Our average value of 7.0 (fig. 5) was similar to the 8.4 obtained by Levine et al. [17].

\section{Statistical Analysis}

Table III lists the correlation coefficients for those parameters that varied significantly with age or body size. In only two instances (cardiac output and stroke volume) was the best correlation obtained with estimated body surface area and even then an equally good correlation was found with height alone. Body surface area is a redundant parameter since it is in turn derived from a regression equation for height and weight. Therefore, surface area was eliminated from the list of independent variables prior to calculation of regression equations.

Table IV lists the linear regression constants and regression equation coefficients for those parameters with an $R$ value above 0.70 . Calculated systemic, total pulmonary and pulmonary arteriolar resistances were inversely related to age, height, and weight. Therefore, it seemed that non-linear regression formulae employing the inverses of age, height and weight would be more suitable. Table $V$ lists the results and shows that this hypothesis was indeed true, with $R$ values exceeding 0.94 .

Separate analyses by sex failed to reveal any consistent differences. Cardiac outputs and other values can be predicted equally well for males or females using the same regression equations. The often quoted differences found between the sexes, when compared on a surface area basis, is probably due to differences in body configuration that are not taken into account by the usual methods for estimating surface area [14].

Fig. 3. Diameter of left ventricular cavity as measured by the method of Levine et al. [17] plotted against age. Fig.4. Left ventricular wall thickness plotted against age. This figure includes 11 subjects from our laboratory at the University of Florida as well as 9 patients from the reference by НАтам et al. [12]. We believe that our inability to distinguish left ventricular wall from thymic tissue accounts for the thicker than expected left ventricular 'wall' in four young patients.

Fig. 5. The ratio of the left ventricular cavity to the wall is essentially a constant. Combined with the regression equations for wall and cavity size this is a useful measurement for determining if an increase in LV size is due to hypertrophy or dilatation. 
Table III. Summary of correlation coefficients

\begin{tabular}{|c|c|c|c|c|c|c|}
\hline Variable & Number & Age & Height & Weight & Heart rate & Surface area \\
\hline Cardiac output & 21 & 0.92 & 0.94 & 0.91 & -0.76 & 0.94 \\
\hline Stroke volume & 21 & 0.89 & 0.89 & 0.87 & - & 0.90 \\
\hline Stroke work & 21 & 0.87 & 0.84 & 0.91 & - & 0.90 \\
\hline Oxygen consumption & 8 & 0.68 & 0.86 & 0.90 & -0.48 & 0.89 \\
\hline Systemic resistance & 21 & 0.70 & -0.78 & -0.57 & 0.78 & -0.69 \\
\hline $\begin{array}{l}\text { Total pulmonary } \\
\text { resistance . . }\end{array}$ & 21 & -0.67 & -0.75 & -0.54 & 0.74 & -0.66 \\
\hline $\begin{array}{l}\text { Pulmonary artery } \\
\text { resistance. . . . }\end{array}$ & 14 & -0.53 & -0.65 & -0.41 & 0.65 & -0.53 \\
\hline $\begin{array}{l}\text { LV cavity. } \\
\text { LV wall . . . . }\end{array}$ & $\begin{array}{l}11 \\
11\end{array}$ & $\begin{array}{l}0.83 \\
0.56\end{array}$ & $\begin{array}{l}0.80 \\
0.55\end{array}$ & $\begin{array}{l}0.83 \\
0.57\end{array}$ & $\begin{array}{l}-0.71 \\
-0.66\end{array}$ & $\begin{array}{l}0.82 \\
0.56\end{array}$ \\
\hline
\end{tabular}

Table IV. Summary of regression coefficients

\begin{tabular}{|c|c|c|c|c|c|c|c|}
\hline Variable & Number & Constant & Height & Weight & Age & H.R. & $\mathbf{R}$ \\
\hline Cardiac output & 20 & -1.33 & 0.044 & 0.035 & -0.124 & - & 0.95 \\
\hline Oxygen consumption ${ }^{1}$ & 72 & 3.03 & 0.961 & 1.469 & 一 & - & 0.74 \\
\hline Stroke volume . . & 21 & -13.81 & 0.386 & 0.423 & - & - & 0.90 \\
\hline Stroke work & 21 & 0.083 & - & 0.011 & 0.009 & - & 0.91 \\
\hline J.eft ventricular wall & 11 & 36.17 & -0.230 & 0.052 & 1.480 & -0.121 & 0.77 \\
\hline Left ventricular cavity & 11 & 189.0 & -1.413 & - & 12.941 & -0.534 & 0.89 \\
\hline Systemic resistance & 21 & 152.3 & -1.450 & 1.045 & 2.852 & - & 0.87 \\
\hline Total pulmonary resistance & 21 & 26.83 & -0.256 & 0.206 & 0.392 & 一 & 0.83 \\
\hline Pulmonary arteriolar resistance & 14 & 20.06 & 0.222 & 0.126 & 0.643 & - & 0.79 \\
\hline
\end{tabular}

${ }^{1}$ Includes data from literature since oxygen consumption was measured in only 8 of our subjects.

Table V. Summary of non-linear regression coefficients

\begin{tabular}{|c|c|c|c|c|c|c|}
\hline Variable & Number & Constant & 1/age & l/ht & $1 / w t$ & $\mathbf{R}$ \\
\hline Systemic pulmonary resistance & 20 & 4.4 & -0.12 & - & 366.6 & 0.98 \\
\hline $\begin{array}{l}\text { Total pulmonary resistance } \\
\text { Pulmonary arteriolar }\end{array}$ & 20 & 0.5 & -0.02 & - & 65.7 & 0.94 \\
\hline resistance. . . . & 12 & 0.6 & 0.03 & 232.8 & - & 0.96 \\
\hline
\end{tabular}

\section{Discussion}

Interest in comparing the physiology of subjects of various sizes requircs a method to allow for accurate comparison of normal data. This has been of particular interest in pediatrics, a field where the pertinent range of body size is large, regardless of whether length, weight or body surface area is considered. These latter functions, as well as total body water, lean body mass, and regression equations utilizing one or more of these parameters have been utilized in an attempt to estimate normal physiologic standards.
Previous studies from this laboratory [14] had shown that estimated surface area is not a valid yardstick for comparison of physiologic data. Cardiac output appeared to be an exception, but the data available were considered too limited in surface area range to be conclusive. One purpose of the present study was to gather further information regarding the validity of comparing hemodynamic data on the basis of estimated surface area.

The proposed relationship between cardiac output and body surface has become generally accepted in clinical practice. Evidence of such acceptance is found 


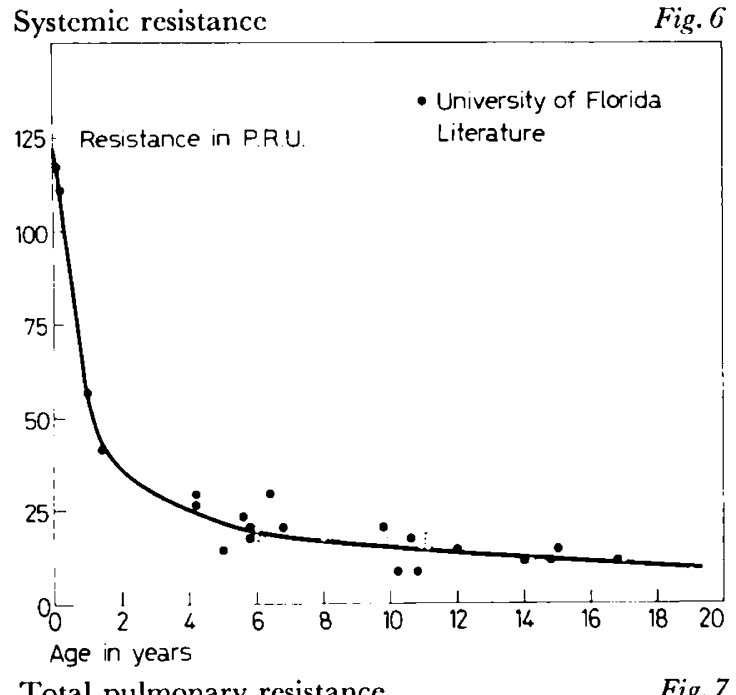

Total pulmonary resistance

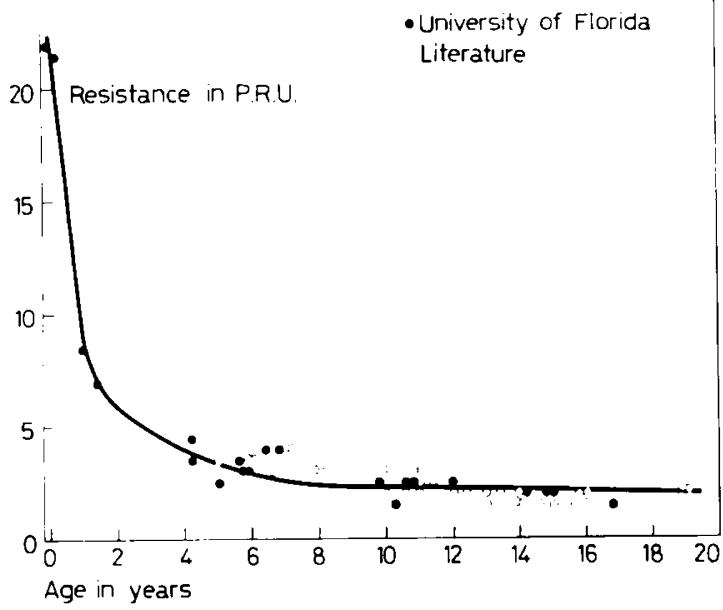

Pulmonary arteriolar resistance

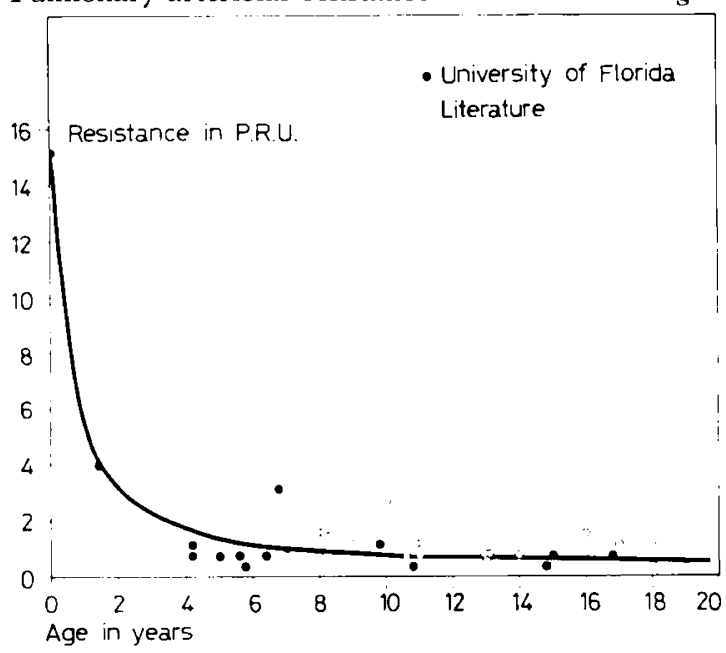

in virtually universal reporting of cardiac output in relation to body surface area by cardiac catheterization laboratories. Indeed the term 'cardiac index' would scem to imply that this is a satisfactory method for measuring onc aspect of the integrity of the cardiovascular system. In spite of common usage, the validity of the cardiac index has been challenged $[2,27,28]$ and defended $[3,5,13,29]$ repeatedly in recent years.

'The best available surface area estimate, namely the nomogram developed by SENDRoY and Ciscchini [25], was applied to our data. Surface area did not offer a significant improvement in predicting normality. Indeed, height alone was better in most instances. The omission of surface area did not significantly lower the correlations obtained using the multiple linear regression method (table VI). For these reasons we favor regression cquations for estimation of normal data, rather than invoking the scmi-abstract concept of body surface area.

Table VI. Multiple correlation coefficients with and without surface area as an independent variable

\begin{tabular}{|c|c|c|}
\hline & $\begin{array}{l}\text { With } \\
\text { S.A. }\end{array}$ & $\begin{array}{l}\text { Without } \\
\text { S.A. }\end{array}$ \\
\hline Cardiac output & 0.962 & 0.962 \\
\hline Oxygen consumption . . . . . & 0.985 & 0.985 \\
\hline Stroke volume. . . . . . . . . & 0.971 & 0.971 \\
\hline Stroke work. . & 0.971 & 0.970 \\
\hline Systemic resistance. . . . . . & 0.922 & 0.884 \\
\hline Total pulmonary resistance . . & 0.902 & 0.843 \\
\hline Pulmonary arteriolar resistance & 0.798 & 0.798 \\
\hline Left ventricular wall . . . . . & 0.774 & 0.772 \\
\hline Left ventricular cavity . . . . & 0.888 & 0.888 \\
\hline
\end{tabular}

\section{Measurement of Vascular Resistance}

The ratio of mean pulmonary artery pressure to that found in the systemic artery after one week of age is relatively constant (fig. 1). This ratio varied from 9 to $22 \%$ with a mean of $15.5 \%$. Our youngest subject had a PA:SA ratio of $18 \%$ at one day of age, while the highest ratio was found in a five-year-old child.

Fig. 6. Systemic resistance plotted against age. Data from references $[1,5,26]$ as well as our own laboratory are included in this as well as the next two figures.

Fig. 7. Total pulmonary resistance plotted against age $[1,4,5,19,24,26]$.

Fig. 8. Pulmonary arteriolar resistance plotted against age $[1,4,5,26]$. 
Figures 6-8 show that calculated resistances for both systemic and pulmonary circulations fall with increasing age at approximately the same rate. We believe that this is a consequence of the definition of resistance. Vascular resistance is commonly considered to be analogous to direct current resistance. This is a grossly oversimplified analogy [15]. It neglects, for example, the pulsatile nature of blood flow and the changes in capacity of the vascular bed. A more correct analogy would be to alternating current in a finite conductor and hence use of the term impedance rather than resistance $[20]$.

In conventional terms, however, as systemic blood flow increases to accommodate the needs of increasing body size, the denominator of the DC resistance term increases and 'resistance' decreases. Since in the absence of shunts, pulmonary blood flow must parallel the increase in systemic blood flow, pulmonary 'resistance' decreases pari passu.

Systemic resistance and pulmonary artery resistance vary inversely with age, height, or weight. Since resistance gradually decreases, it is difficult to decide where it becomes tangent to the $\mathrm{x}$-axis. In other words, when does pulmonary vascular resistance stabilize and reach adult levels? Since PA:SA pressure and pulmonary artery pressure are constant after the first week of life, the answer obviously depends on when the cardiac output reaches adult levels. Cardiac output in turn depends upon, among other things, body size, which obviously does not reach adult levels until late in childhood. Except for the adolescent years, the rate of growth slows progressively with increasing age. Calculated resistances will perforce decline slowly until about the same age. The extrapolation of resistance data to imply that the pulmonary vascular bed does not mature for several years [19] is misleading.

\section{Summary}

Twenty-nine apparently normal children under 20 years of age were catheterized. There was no correlation of intracardiac and great vessel pressures with either age or increasing body size. In addition to conventional cardiac catheterization data, left ventricular cavity and wall thickness were recorded for 11 children using angiocardiographic techniques. Correlation coefficients were calculated for all items of cardiac cathcterization data and compared to age, heart rates and measurements of body size. In only two instances (cardiac output and stroke volume) was best correlation obtained with body surface area; even then an equally good correlation was found with height alone. Furthermore, body surface area is a redundant parameter since it is in turn derived from a regression equa- tion for height and weight. The omission of surface area did not significantly lower the correlation obtained from the multiple linear regression method. The authors suggest that multiple regression equations be used instead of surface area for assessing normal hemodynamic values.

\section{Appendix}

The use of regression equations implies only that the given variable may be described by addition of constants and coefficients modifying certain easily ascertainable parameters for the patient. These regression equations are extremely simple to use. For example, the regression equation for predicting cardiac output is:

Predicted cardiac output $=-1.33-0.124$ (Age) $+0.044(\mathrm{Ht})+0.035(\mathrm{Wt})$.

Values for the subject are inserted as age in years, height in centimeters and weight in kilograms. For example, one of our patients with endocardial fibroelastosis had the following values:

Predicted cardiac output $=$

$$
\begin{aligned}
& -1.33-0.124(0.197)+0.044(60)+0.035(5.4) \\
& -1.33-0.02+2.64+0.19 \\
& +1.48 \mathrm{l} / \mathrm{min}
\end{aligned}
$$

The observed cardiac output was only $0.65 \mathrm{l} / \mathrm{min}$ or $56 \%$ less than expected.

Non-linear regression equations are handled in an analogous manner. Thus predicted systemic resistance for this same child would be given by the following formula :

Predicted systemic resistance $=$

$$
\begin{aligned}
& 4.4-0.12 /(\text { Age })+\frac{366.6}{W \mathrm{Wt}} \\
& 4.4-0.12 / 0.197+366.6 / 5.4 \\
& 71.5 \mathrm{PRU}
\end{aligned}
$$

\section{References and Notes}

1. Barratt-Boyes, B.G. and Wood, E.H.: Cardiac output and related measurements and pressure values in the right heart and associated vessels, together with an analysis of the hemodynamic response to the inhalation of high oxygen mixtures in healthy subjects. J. Lab. clin. Med. 51: 72 (1958).

2. BRANdFonbrener, M.; LANdowne, M. and Shock, N.W.: Changes in cardiac output with age. Circulation 12: 557 (1955). 
3. Brotmacher, L. and Deuchar, D. C.: The systemic blood flow in congenital heart disease, with an examination of the validity of the cardiac index. Clin. Sci. 15: 441 (1956).

4. Brotmacher, L. and Freming, P.: Cardiac output and vascular pressures in 10 normal children and adolescents. Guy's Hosp. Rep. 106: 268 (1957).

5. Cayler, G. C. ; Rudolph, A. M. and Nadas, A.S. : Systemic blood flow in infants and children with and without heart disease. Pediatrics 32: 186 (1963).

6. Cournand, A. and Ranges, H.A.: Catheterization of right auricle in man. Proc. Soc. exp. Biol., N.Y. 46: 452 (1941).

7. Dixon, W.J., ed.: BMD, Biomedical computer programs, health sciences computing facility (University of California, Los Angeles 1964).

8. Emmanouilides, G. C.; Moss, A.J.; Duffie, E. R., Jr. and Adams, F.H.: Pulmonary arterial pressure changes in human newborn infants from birth to three days of age. J.Pediat. 65: 327 (1964).

9. Fairchild, B.T. and Krovetz, L.J.: Ten circuits for differentiation on analog computers. Control Engineering 12: 65 (1965).

10. Forssmann, W.: Die Sondierung des rechten Herzens. Klin.Wschr. 8: 2085 (1929).

11. Gleason, W.L. and Braunwald, E.: Studies on the first derivative of the ventricular pressure pulse in man. J. clin. Invest. 41: 80 (1962).

12. Hatam, K.; Runhe, U. and Wallgren, G.: Left ventricular wall dimensions: An angiocardiographic study of the normal variation in children. Amer. J. Cardiol. 15: 815 (1965).

13. Jegler, W.; Sekelj, P.; Auld, P.A. M.; Simpson, R. and McGregor, M.: The relation between cardiac output and body size. Brit. Heart J. 25: 425 (1963).

14. Krovetz, L.J.: The physiologic meaning of body surface area. J. Pediat. 67: 841 (1965).

15. KuidA, H.: General relations of flow and pressure. Ann. N.Y.Acad.Sci. 127: 364 (1965).

16. Levine, H.J.; Neil.l, W.A.; Wayman, R.J.; KrasNow, N. and Goris, R.: The effect of exercise on mean left ventricular ejection rate in man. J.clin. Invest. 41: 1050 (1962).

17. Levine, N.D.; Rockoff, S.D. and Braunwald, E.: An angiocardiographic analysis of the thickness of the left ventricular wall and cavity in aortic stenosis and other valvular lesions. Circulation 28 : 339 (1963).

18. Lind, J.: The human foetal circulation and its changes following birth. Die physiologische Entwicklung des Kindes; ed. F.LinNEWEH, p. 105 (Springer, Berlin 1959).
19. Lucas, R.V., Jr.; St. Geme, J.W., Jr.; Anderson, R.C.; Adams, P., Jr. and Ferguson, D.F.: Maturation of the pulmonary vascular bed. A physiologic and anatomic correlation in infants and children. Amer.J. Dis. Child. 101: 467 (1961).

20. McDonald, D.A. : Blood Flow in Arteries; p. 328 (Williams \& Wilkins, Baltimore 1960).

21. Miller, G.A.H.; Kirklin, J.W. and Swan, H.J. C.: Myocardial function and left ventricular volumes in acquired valvular insufficiency. Circulation 31: 374 (1965).

22. Nickerson, L.J.; Warrén, J.V. and Brannon, E.S.: The cardiac output in man: studies with the low frequency, critically-damped ballistrocardiography and the method of right atrial catheterization. J.clin. Invest. 26: 1 (1947).

23. Reeves, J.T.; Grover, R.F.; Blount, S.G., Jr. and FilleY, G.F.: Cardiac output response to standing and treadmill walking. J.appl. Physiol. 16: 283 (1961).

24. Rotta, A.; Canepa, A.; Hurtado, A.; VelasQuez, T. and Chavez, R.: Pulmonary circulation at sea level and at high altitudes. J. appl. Physiol. 9: 328 (1956).

25. Sendroy, J., Jr. and Cecchini, L. P.: Determination of human body surface area from height and weight. J.appl. Physiol. 7: 1 (1954).

26. Sproul, A. and Simpson, E.: Stroke volume and related hemodynamic data in normal children. Pediatrics 33: 912 (1964).

27. TANner, J.M.: Fallacy of per-weight and persurface area standards, and their relation to spurious corrclation. J.appl. Physiol. 2: 1 (1949).

28. TANNER, J.M.: The construction of normal standards for cardiac output in man. J. clin. Invest. 28: 567 (1949).

29. TAYlor, H.L. and Tiede, K.: A comparison of the estimation of the basal cardiac output from a linear formula and the 'cardiac index'. J.clin. Invest. 31: 209 (1952).

30. The authors wish to thank Dr. Clyde Williams, Chairman, Department of Radiology, who reviewed the thoracic roentgenograms. We also wish to thank Drs. J. Russell Green, Jr., and Joseph Linhart who performed four of the catheterizations in the older children. Drs. Glenn Cayler and Russell Lucas kindly furnished data in addition to that available in their published reports to enable us to include their patients.

31. Supported in part by grants from the Florida Heart Association, Developmental Physiology Training Grant ( $\left.\mathrm{T}_{1}-\mathrm{HD}-54\right)$ and Cardiovascular Training Grant (3T - HE-5493-04 $\left[\mathrm{S}_{1}\right]$. Dr. Krovetz is the recipient of a Research Career Development Award (5K3-9761-02). 